published in the Therapentisone Monatshefte the result of radiugraphic examinations and demonstrated the displacement of the diaphragm in cases of chlorosis and other similar diseases. Such cases, no doubt, exist, but in medical science it is desirable to avoid generalising too hastily. I had recently an opportunity of observing several cases in which the apex beat was really displaced outwards but not downwards ; it was even found to be in the fourth intercostal space. I think that in those cases there is no dilatation at all, but $I$ find it imprudent to deny completely the possibility of dilatation in chlorosis. Botb are possible, and it may be said that in many cases of chlorosis and anæmia there exists a dilatation of the beart cavities causing an increase in the size of the heart dulness, the apez beat being di.placed outwards and downwards. On the other hand, dilatation may be only simulated by a displacement of the diapuragm causing the great diameter of the heart to be more horiz ontal and the apex-beat to be displaced outwards and downwards.

I saw once a very tall youth, aged 16 years, who was in a very bad condition of health which was caused by improper hygienic conditions. He suffered from pain in the epigastrium, and examination revealed only an enlargement of the left ventricle. After several days of absolute rest this dilatation ceased and the limits of the heart became normal. There was no murmur to be heard, but there was cyclic albuminuria which appeared every afternoon. The patient left the hospital after a week's treatment, and soon afterwards (in five weeks) came back wich his heart considerably enlarged. Rest and appropriate diet sufficed to restore him a second time, but the cyclic albuminuria remained. Such cases occucring amongst young men may also be considered as a frequent cause of heart dilatation. The muscular wall of the ventricle being in a bad state of nutrition, the blood is incapable of nourishing the muscle cells.

With regard to the treatment in cases of anæmia the greatest importance should be attached to the functional state of the heart. In many cases, especially in commencing chlorosis, walking and other forms of exercise are recommended and often with a good result, but in more advanced cases absolute rest is necessary in order to strengthen the heart and to prevent oppression, \&c. It is interesting to notice that in general the patients complain not only of heart palpitation but of pain in the epigastrium. Many of them, having a well-marked heart dilatation, do not notice any abnormal feeling in the præcordial area, and the epigastric pain often disappears when the dulness regains its normal size.

In a bathing-place like Spa, where hydropathic treatment is almost always combined with the internal use of the ferruginous waters, the examination of the heart must never be omitted; indeed, stimulating the circulation and torpid nervous system will greatly help the internal action of the absorbed iron. That combined action, indeed, gives the best result. In cases, however, where the heart is enlarged and the oppression is intense and in some other cases the use of douches may be dangerous, the patient not being able to stand the sudden shock of the water. In such cases baths of natural carbonic acid water are generally found very useful.

Baths of carbonic acid water may be given in cases of chlorosis and anæmia with increase in the area of cardiac dul. ness. (Palpitation may be nervous and is not a criterion as to the condition of the heart; pure nervous palpitation is often improved by hydropathic treatment with cold water.) As already mentioned the heart becomes enlarged because the blood-pressure is too strong for its feeble muscle. The carbonic acid bath causes a gentle but general action on all parts of the skin. Soon after entering it the patient feels the bubbles of carbonic acid on every part of his body and the skin becomes red, the peripheral vessels are dilated, and the pulse becomes markedly slower and increases in strength. All cutaneous blood-vessels dilate, thereby diminishing the work of the heart. It is, of course, in the rame manner that the baths of Nauheim ro greatly improve many cases of heart disease-namely, by diminishing the pressure in the vascular system. Indeer, carbonic acid baths, associated with the internal use of chalybeate water, give the best results in the treatment of anæmia with heart weakness. It is necessary to ascertain the extent of the heart-dulness accurately in order to determine whether exercise or rest is required in the treatment or whether douches or baths will be the more efficacions.
Potain and Vaquez: Semaine Médicale, 1895, p. 415. Von Noorden : Die Bleichsucht, Notbnagel's Specielle Pathologie und Therapie, Band viii., 1. Griinmach: Therapeutische Monatsbefte 1897, 1. Talma Nederlandsch Tijdschrift voor Geneeskunde, 1895, 10 Muiller: Berlines Klinische Wochenschrift, 1895, 38 Henschen: Fischer, Jeva, 1898 Glax : IIandbuch der Balneotherapie, Band ii., 1900. Spa, Belgium.

\section{CASE OF SUPRA-HEPATIC HYDATID CYST.}

\section{BY GEORGE W. DAVIS, M.D., B.S. DURH. L.R.C.P. LOND., M.R.C.S. ENG.}

THIS was a hydatid of about 25 ounces capacity situated between the liver and the diaphragm. The diagnosis was difficult even beyond the generality of hydatids. The patient had a healthy appearance and there was an absence of any concrete symptoms other than that of the percussion outline and skiagram.

A symptom of remarkable character was the diminished urination, almost amounting to anuria, which in association with menorrhagia and slight swelling of the legs was evidently due to pressure on the rena cava by the cyst, probably at the point of the passage of the vein through the diaphragm.

In spite of the apparent well-being of the patient her life was imperceptibly but very definitely ebbing away. She was very gradually losing strength and energy ; from being a woman who took an active part in the household management she could merely lie on her bed or sofa, walk short distances, and go about in a bath chair, and even this slight exertion was accomplished with increasing difficulty.

The case was sten by Sir William Broadbent, Bart., by Mr. Charters Symonds, by Mr. Golding-Bird, by Mr. G. H. Makins, by Mr. F. G. Larkin, and by Dr. Barry Blacker. She was first seen by. me on Nov. 12th, 1888 The operations were performed on April 12th and 16th, 1899, by Mr. G. H. Makins and the convalescent period extended over two and a half months, during the whole of which time there was much danger of septic infection from the character of the walls of the cyst which kept it gaping and in continual movement.

The patient was a multipara, aged 36 years, and had four healthy children between the ages of seren and 16 years. Her father died from enlargement of the liver at 60 years of age, her mother died from "cancer" at 60 years of age, and an aunt is suffering from multiple abdominal tumours the character of which have not been diagnosed. She has eight brothers and two sisters alive and bealthy. Except for confinements and three miscarriages the patient had never ailed until 1894 when Mr. F. G. Larkin discovered the abdominal hydatid which was removed by operation in two stages by Mr. Charters Symonds.

On Nov. 12th, 1898, I was first consulted on account of blood passed by the bowel, apparently due to some obstruc. tion of the vena portæ. This led to a careful examination of the liver, but it will be easier to grasp the main facts of the ca:e by reviewing the chief symptoms separately during the period of five months preceding the operation, then describing the operation, and afterwards the convalescence.

The patien was fair-complexioned, fresh in colour, very young looking, and had such an appearance of absolute health that it was extremely difficult to impress upon the minds of those who saw her for the first time that actually she was seriously ill - as a matter of fact, fading gradually both as to weight and strength. Her weight in November, 1898 , was 8 st. $12 \mathrm{lb}$., and in April, 1899, it was but 8 st. The difficulties of obtaining recognition of the gravity of her condition were further increased by the fact of her occasional improvement in health. Thus at one time she regained $4 \mathrm{lb}$.

The entire right chest was ratber more prominent than the left chest, the measurements being $15 \frac{1}{8}$ inches on the right side and $14 \frac{1}{4}$ inches on the left. The dulness of the liver by percussion-the arms being extended by the side of the head-was seven inches vertically in the middle line, five inches on the right side of the enciform cartilage, and five inches in the posterior axillary line. The dulness could not be defined posteriorly. I found that I could percuss ont the liver much more correctly when standing to the left of the patient (Fig. 1).

The dome-like character of the cyst made it difficult to define by percussion and in liebruary I had a skiagram taken 
by Dr. Barry Blacker which assisted materially in supporting the diagnosis by percussion and showed most definitely the globular outline of the cyst (Fig. 2). Pain was felt occasionally at the side of the right chest and any pressure on the

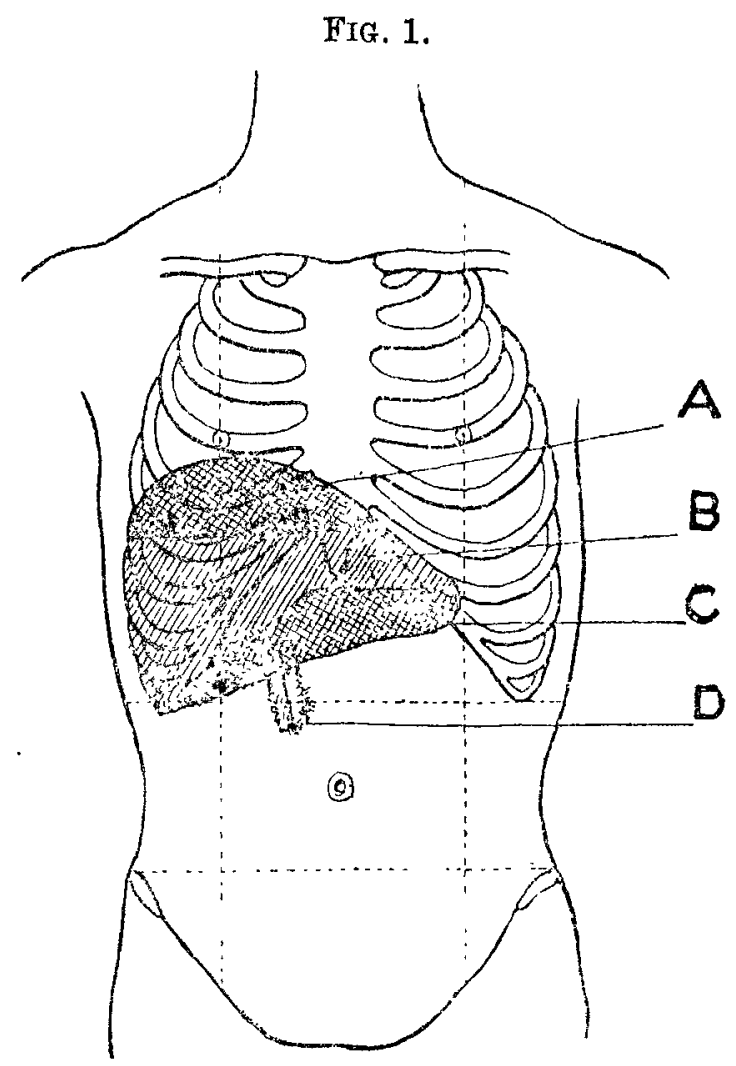

A, Actual line of dulness. $B$, Normal liver outline. C, Actual line of dulness. $D$, Scar of previous operation.

liver below the ribs caused much pain. The patient's lcss of energy may be estimated from the fact that in June, 1898, she cycled for four miles on several occa-ions, but by Murch, 1899, she could only walk with difficulty, and even bath-chair exercise exhausted her so much that she came

\section{Fig. 2.}

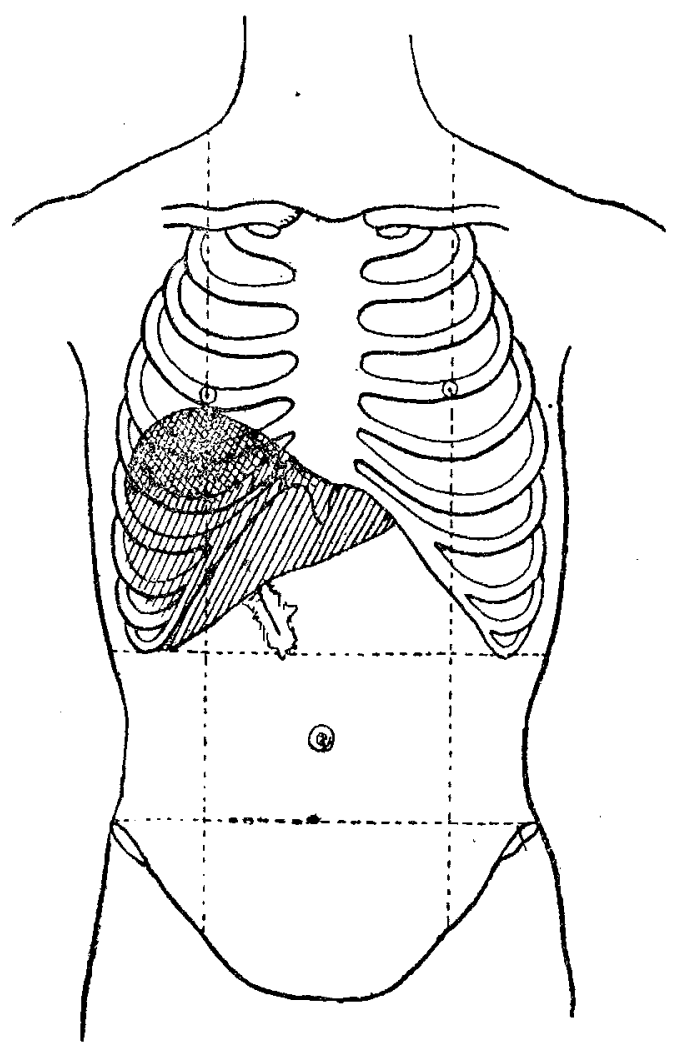

To show the spherical eminence as ilefined by ski igram.

home blue about the lips, faint and miserable. Menstruation was much more profuse and often the flow would occur in gushes.

The diminution of urine passed was a most remarkable symptom and was doubtless due to pressure by the cyst on the vena cava as it passed through the diaphragm, causing by the venous obstruction a lessened blood flow through the kidneys. There were no uramic symptom and no colliquative sweating. The urine was of average specific gravicy and contained no abnormal constituents. The arnount of urine passed in 24 hours was as follows:-

\begin{tabular}{cc|c|c|c|c}
\hline & $\begin{array}{c}\text { Number of } \\
\text { observations. }\end{array}$ & $\begin{array}{c}\text { Average } \\
\text { ounces. }\end{array}$ & $\begin{array}{c}\text { Maximum } \\
\text { ouncer. }\end{array}$ & $\begin{array}{c}\text { Minimum } \\
\text { ounces. }\end{array}$ \\
\hline November, 1898 ... & 9 & 18 & 28 & 18 \\
December, 1898 ... & 17 & $12 \frac{1}{2}$ & 20 & 5 \\
January, 1899 & $\ldots$ & 24 & $12 \frac{1}{2}$ & 24 & 4 \\
February, 1899 & $\ldots$ & 24 & 14 & 25 & 6 \\
March, 1899... & $\ldots$ & 24 & 10 & 19 & 3 \\
\hline
\end{tabular}

The amount of fluid taken at this time averaged about 30 ounces in 24 hours.

Her temperature ranged between $96.4^{\circ}$ and $98^{\circ} \mathrm{F}$., but was subnormal for the entire period. The approximate averages were as follows:-November, $98^{\circ}$; December, $97 \cdot 8^{\circ}$; January, $975^{\circ}$; February, 97.6 $6^{\circ}$ and March, 97. $4^{\circ}$. The pulse, which was poor in quality, was very constant, about 72. The respiration was about an average of 22 . The nervous symptoms may he described as some increase of the left knee reflex, much vertical headache, and sleeplessness.

As already mentioned, the operations for the removal of the cyst were performed on April 12th and 16th, 1899, by Mr. G. H. Makins. The patient having been prepared in the usual manner at $9.30 \mathrm{~A} \mathrm{M}$. gas and ether were administered by $\mathrm{Mr}$. Walter Tyrrell; a central vertical incision was made below the ensiform cartilage and through this the lower surface of the liver was explored with negative result as to any secondary cyst. A long exploring needle was now thrust into the liver and at the fourth thrust sufficient fluid was obtained to confirm the diagnosis by the discovery of many hooklets. The central incision was now closed and about two inches of the seventh rib were resected in the right mid-axillary line, the intercostal muscles and both parietal and visceral layers of the pleura were divided and stitched around the opening left by the resection of the rib, leaving the cyst wall apparent On April 16th Mr. Walter Tyrrell gave the anæsthetic at 11.30 A.M. A crucial incision was made into the cyst to the extent of the opening, and from 25 to 30 ounces of lemon-coloured fluid came away. No daughter cysts were precent. The hyaline cyst floated free within the cavity and was so friable as to be with difficulty removed by means of ovum forceps. The cavity was six and a half inches across. A large drainage-tube was put right into it and the whole was dressed in the usual manner. The temperature rose until on April 19th it reached $103^{\circ}$ and did not become normal until May 9th. An ice cradle was kept on whenever the temperature reached $100^{\circ}$ until April 25th. On April 24th I aspirated in the sixth space at the back of the right chest and removed two ounces of highly coagulable fluid. Sloughs pieces of cyst wall continued to come away until a month after the operation. The cyst cavity was prevented from bridging over and closing superficially before it closed deeply by gauze packing and by the drainage-tube being kept in for a long time (it was not removed until June 3rd, 1899). Twice daily for five weeks I syringed the cyst out with solution of creolin $(1$ in 160) and then introduced some emulsion of europhen in glycerine and iodoform ganze. All dressings were sterilised by steam before use throughout the convalescence. The right chest was strapped from May 12th onwards until the sinus completely closed.

On June 19th the patient left for the seaside and passed from my observation for a month and at the end of that time she was completely cured.

This case appears to be important to record for two reasons. Firstly, it well illustrates that the history of a case of hydatid is often that of a deterioration of health so gradual as to be impercextible to the patient's friends, but which is measurably demonstrable if a strict record of the patient's powers is taken at intervals. If this deterioration is not arrested, by removal of the cyst, before the patient has become too weak to bear the exhaustion entailed by a necessarily debilitating convalescence the end of such a case, apart from suppuration or bursting of the cyst, must be death after the failure of force has gradually deprived the victim of function by function until the whole gamut has been passed from perfect enjoyment of full energy to a mere 
bedridden existence. The second point is of extreme interest physiologically as showing the marked dimination of urinary secretion which follows obstruction to the venous outflow from the kidney by pressure on the inferior vena cava.

Sidcup, Kent.

\section{a dettirtor \\ or}

\section{HOSPITAL PRACTICE, BRITISH AND FOREIGN.}

Sulla autem est alia pro certo noscendi via, nisi quamplurimas et morborum et dissectionum historias, tum aliorum tum proprias collectas hubere, et inter
Morb., lib. iv. Procemium.

\section{TOTTENHAM HOSPITAL.}

A CASE OF AN UNUSUAL FORM OF INTUSSUSCEPTION.

\section{(Under the care of Mr. Herbert W. CARSON.)}

IN infants under the age of six months intussusception is always a very serious condition, even though laparotomy be performed early, but if when the abdomen has been opened it is not possible to reduce the intussusception the prognosis is extremely grave, for whatever method of treatment be adopted a fatal result is almost certain to ensue. Three courses are open to the surgeon: in the first place he may incise the ensheathing layer and may then excise the included bowel; or secondly, he may excise the whole intussusception, performing anastomosis between the healthy bowel above and the healthy bowel below; or lastly, a portion of the bowel immediately above the invagination may be brought up to the surface and an artificial anus made. Inasmuch as shock is the main cause of death after operation for intussusception in infants it is probable that the last method will give the best results. The complexity of the intussusception in the case recorded below is indeed remarkable.

A female, aged fire months, was admitted into the Tottenham Hospital on May 14th, 1900, with an abdominal tumour and a history of passing blood and mucus. The child was quite well till the 9th, when she had diarrbœa, passed a little blood, and "the bowel came down." This was replaced by the mother who then obtained medical advice. No tumour was then felt in the abdomen; the child looked fairly well and was not sick. On the 12 th the bowels acted and the child vomited after a screaming fit. There was no further sickness before admission to the hospital, but slime and blood were passed per rectum on the 13 th and 14th (the day of admission).

On admission the child was quiet, the pulse was fair, and her general condition was good. There was no abdominal distension. A definite small tumour was felt in the left lumbar region above and internal to the anterior superior spine. Per rectum the sphincter was found to be relaxed. The presenting part of an intussusception was felt just above the internal sphincter having two openings, the lumen of the bowel and the mouth of the appendix. As seen per speculum the presenting mass was of a brownish-grey colour. An unsuccessful attempt had been made to reduce the intussusception by injections.

Under chloroform the abdomen was opened a little to the left of the middle line and the intussusception was easily found in the situation of the lower part of the descending colon. It measured some five or six inches in length. At the upper end the ileum entered the intussusception and the lower end presented an almost identical appearance, with the exception that the rectum took the place of the ileum. Attempts at reduction proving unsuccessful the tumour was drawn outside the abdomen and shut off from the peritoneal cavity, and the intussuscipiens was opened by the longitudinal incision recommended by Barker, the ileum and ensheathing layer having been first united by interrupted sutures. The intussusceptum was then cut through in situ at the upper part, as it was impossible to bring it through the incision. This resulted in freeing a deeply congested portion of bowel about two inches long having the mucous membrane external. The rectum was then easily reduced and clamped. The intussuscipiens was then found to consist of four layers measuring 15 inches when unfolded. The upper and lower ends of this at the ileo-crecal junction and at the junction of the colon with the sigmoid flexure were so congested that there was no alternative but to excise the whole of it. This was done and the ileum was united to the rectum over a bone bobbin. The patient died about an hour after returning to bed.

Remarks by Mr. CARSON.- This case seems to be a good instance of those rare cases of intussusception in which "a descending intussusception is associated with an ascending one, the two occupying the same segment of bowel."1 The accompanying diagram will make the condition clearer, the

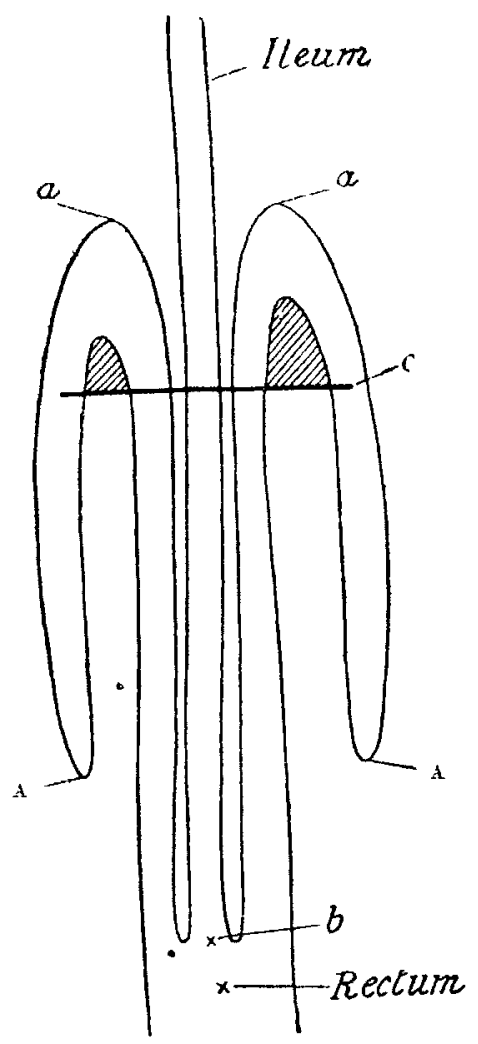

$a$ and $A$ were firmly adherent to ileum and rectum freeing the small shaded part.

intervals between the layers being left for the sake of clearness. In the present case the descending intussusception was of the ileo-cral type, the ascending one being of the colic variety, and thus differs from the case quoted by Mr. Treves ${ }^{2}$ in which the descending and ascending intussusceptions were both colic in origin. Mr. Treves also quotes from Leichtenstern who gives eight cases of double intussusception, and from M. Besnier and Noth. nagel, in the latter cases the double intussusception being in the large intestine and occurring in cases of chronic obstruction. The only case I can find in recent literature which at all resembles the one detailed above is that described by Mr. W. H. Brown ${ }^{3}$ in which an ileo-cæcal (?) intussusception was complicated by a short longitudinal fold of the intussusception on itself. The dilatation of the sphincter so often noted in cases of intussusception was well marked in this case. It would be interesting to know whether in replacing "the bowel which came down" the mother really reduced a mere prolapse of the rectum or pushed back the advancing apex of the intussusception. Taking into consideration the condition of the child on admission it seems improbable that the apex of the intussusception could have been at the sphincter from the 9th to the 14th (six days), though the condition of the bowel itself pointed to a somewhat prolonged strangulation.

\section{ST. MARY'S HOSPITAL, MANCHESTER.}

A CASE OF CARAREAN SECTION IN A PRIMIPARA ON ACCOUNT OF THE PELVIC CAVITY BEING BLOCKED BY A FIBROID TUMOUR OF THE UTERUS; RECOVERY; CHILD IIVING.

(Under the care of Dr. LLOYD ROBERTS.)

IN the following very interesting case of Cæsarean section the employment of anti-streptococcic serum seems to have

1 Treves : Intestinal Obstruction, p. 152

3 The LaNCE'1, August 20th, 1898, p. 484. 